\title{
Predictive Factors of Mortality in Acute Aluminum Phosphide Poisoning: 5 Years Retrospective Study in Tanta Poison Control Unit
}

\author{
Ghada Nabil El-Sarnagawy ${ }^{1}$ \\ ${ }^{1}$ Department of Forensic Medicine and Clinical Toxicology, Faculty of Medicine, Tanta University, Egypt
}

\begin{abstract}
Introduction: Aluminum phosphide (ALP) is a widely used rodenticide for grain preservation. Acute aluminum phosphide poisoning became one of the serious public health problems especially in developing countries due to its high mortality rates. Aim of the work: The aim of the present study was to evaluate the predictive factors of mortality from acute ALP poisoned cases admitted to Tanta Poison Control Unit in a 5 years interval from the start of January 2012 to the end of December 2016. Patients and methods: This retrospective study was performed on medical records of acute ALP poisoned patients admitted to Tanta Poison Control Unit during the 5 years period. Patients were divided according to their outcome into survivors and non-survivors. For all patients; sociodemographic data, toxicological data, physical examination, laboratory investigation and therapeutic intervention were recorded to evaluate their associations with the patients' outcome. Results: During the five years period, 105 acute ALP poisoned patients were admitted with $44.7 \%$ deaths. There was significant association between each of young age group, rural residence, suicidal ingestion, increase toxic dose and prehospitalization period with the risk of mortality. Other prognostic factors included altered consciousness, agitations, hypokalemia, hypernatremia, hyperglycemia, elevated (liver enzymes, blood urea\& serum creatinine), need of mechanical ventilation, increased vasoactive drug administration and low magnesium sulphate administration were also associated with poor outcome. Moreover, presence of abnormal ECG, metabolic acidosis and low systolic blood pressure at admission were associated with high risk of mortality (odd ratios were 48.488, 10.251 and 0.964 respectively). Conclusion: Early recognition of the alarming risk factors with proper medical intervention may improve patients' outcome and decrease the mortality rate of acute aluminum phosphide poisoning. Recommendations: Owing to the increase mortality rates of ALP poisoning, it is recommended to make restrictions of its open sales and perform a safe manufacture forms in a not ingestible containers.
\end{abstract}

Keywords Aluminum phosphide, poisoning, mortality, prediction

\begin{abstract}
Introduction
Gor decades, aluminum phosphide (ALP) is a commonly used as grain rodenticides throughout the world due to its wide availability, low cost, high effectiveness with harmless decomposition products (Hassanian-Moghaddam and Pajoumant, 2007; EtemadiAleagha et al., 2015). It is available as tablets of Celphos, Alphos or Quickphos which are known as rice tablets. Each tablet weights 3 grams and contains $56 \%$ ALP and $44 \%$ of aluminum carbonate and paraffin (Goel and Aggarwal, 2007; Moghadamnia, 2012).

The incidence of ALP poisoning increased steadily specially in developing countries (Meena et al., 2015).To the greatest extent, most reports of aluminum phosphide poisoning were suicidal especially in young adult, although accidental poisoning may occur during occupational exposure (Hosseinian et al., 2011; Chaudhary et al., 2013).
\end{abstract}

Upon contact with moisture or gastric acidity, ALP releases highly toxic phosphine gas (Mehrpour et al., 2012).It is rapidly absorbed causing systemic toxicity and cellular hypoxia by inhibition of mitochondrial cytochrome $\mathrm{C}$ oxidase enzyme. Moreover, phosphine gas induces oxidative stress via catalase inhibition and increased free radicals formation (Moghadamnia, 2012; Singh et al., 2014). Methehemoglobinemia, hemolysis and inhibition of cholinesterase enzyme have been reported as another mechanisms of ALP toxicity (Saidi and Shojaie et al., 2012; Farahani et al., 2016; Wahdan and Elmadah, 2016).

The clinical presentation varies according to the route of administration. After inhalation of phosphine gas, patients may presented with signs of mucous membrane irritation, headache and dizziness in mild cases. Acute respiratory distress syndrome, congestive heart failure and coma may occur in severe cases (Wahab et al., 2008). On 
the other hand, ingestion of ALP causes mild gastrointestinal (GIT) manifestations as nausea, vomiting, abdominal pain, in addition to chest tightness, hypotension, headache and dizziness. In severe cases, GIT hemorrhage, shock, severe metabolic acidosis, cardiac arrhythmia, convulsions and coma may occur. Later, signs of hepatic damage and renal insufficiency may develop (Hassanian- Moghaddam and Pajoumand, 2007).

Death usually occurs in $30-70 \%$ of cases resulting from refractory cardiogenic shock, cardiac arrhythmia, severe hypotension and metabolic acidosis (Nejad et al., 2012; Taghaddosinejad et al., 2016).Unfortunately, management of cases is mainly supportive without specific antidote causing high mortality rate (Agrawal et al., 2015). Determination of predictive factors of mortality at admission may allow more intensive monitoring and treatment that may improve patients' outcome. Therefore, the aim of the present study was to evaluate the predictive factors of mortality from acute ALP poisoned cases admitted to Tanta Poison Control Unit in a 5 years interval from the start of January 2012 to the end of December 2016.

\section{Patients and methods}

\section{I-Study design and ethical consideration:}

This retrospective study was conducted in Tanta Poison Control Unit in a 5years interval from the start of January 2012 to the end of December 2016. Data were collected from the patients' medical records and available documentation in the hospital archive.The study was approved by the head of the Poison Control Center and the Research Ethical Committee of Tanta Faculty of Medicine. Confidentiality of records was conserved by keeping the records anonymous.

\section{II- Patients:}

All patients with acute ALP poisoning were included in this study. The diagnosis was based on history of exposure (either obtained from the patient or the adjoining relative) and presence of symptoms and signs of acute ALP intoxication at admission. Patients were excluded if they had history of co-ingestion with other drugs, declared dead on admission or just cardiopulmonary resuscitation was done for them in the emergency department. Additionally, incomplete records of the patients were excluded.

\section{III-Methods:}

The patients' sheets were revised for the following items; personal data (patient code, age, sex, residence and date of admission) and toxicological data (ingested dose, mode \& route of exposure and prehospitalization period).

Clinical evaluation including initial vital signs (blood pressure, pulse rate, respiratory rate and temperature), physical examination were performed at admission. Initial Glasgow Coma Score (GCS) and poisoning severity score (PSS) were recorded at admission according to Teasdale and Jennett (1974); Persson et al. (1998) respectively.
Routine laboratory investigation including arterial blood gases $(\mathrm{ABG})$, serum electrolytes, liver \& kidney function tests and electrocardiography (ECG) were noted to all patients on hospital admission. Additionally, the need of endotracheal intubation\& mechanical ventilation, vasoactive drugs administration and hospitalization period were documented. Patients were divided into two groups according to main outcome; either survivors or non-survivors.

\section{Statistical analysis:}

Statistical analysis and presentation of data was conducted using SPSS (Statistical Package for the Social Science) version 20 computer program. Qualitative data were expressed as number and percentages in brackets and Pearson's Chi square test was used to examine association between two variables. For quantitative data, the Shapiro-Wilk test for normality was performed and Mann Whitney U and Student's T tests were used for comparison between the studied groups. Binary logistic regression analysis was performed to ascertain the effects of clinically relevant variable on the likelihood that participants have poor outcome. Significance was adopted at $\mathrm{p}<0.05$ for interpretation of results of tests (Dawson-Saunders and Trapp, 2001).

\section{Results}

The present study revealed that, there were 9394 patients admitted to poison Control Unit with $77(0.8 \%)$ deaths in the period between 2012 and 2016 years. Out of all cases, 105 acute ALP poisoned patients were recorded with 47 (44.7\%) deaths. Concerning death rate from acute ALP poisoning, the highest rate $(46.8 \%)$ was in 2016 while the lowest $(6.3 \%)$ was in 2013 (Table 1).

In this study, the age of acute aluminum phosphide poisoned patients ranged from one to 56 years with median age 18 years. The majority of patients were female $(57.1 \%)$, in the age group $10-20$ years $(41 \%)$ and from rural regions $(70.5 \%)$.There was statistical significant difference between survivors and nonsurvivors as regard age and residence. However, gender did not show any significant difference between both groups (Table 2).

Regarding toxicological data, oral route represented the main route of exposure $(85.7 \%)$ and the majority of poisoning (72.4\%) occurred by alleged suicidal intention. The amount of ingestion ranged from 0.25 to two tablets with median of one tablet. The median of pre-hospitalization period was two hours (ranged from one to 18 hours). There was significant association between each of the mode of exposure, the ingested dose $\&$ the per-hospitalization period and mortality (Table 2).

Table (3) showed that the non-survivors had significantly lower systolic and diastolic blood pressure than survivor group. Meanwhile, pulse, temperature and respiratory rate did not show any significant difference between both groups.

Table (4) demonstrated that the majority of nonsurvivor group had severe GCS and PSS, while, the greatest part of survivor patients had normal GCS and 
mild PSS. Moreover, agitation was significantly associated with the outcome as it presented in $27.7 \%$ in non-survivors. However, no significant association could be observed between GIT manifestations and patients' outcome.

Table (5) revealed significant difference between both groups considering all investigations parameters. The non-survivor group had significantly increased levels of serum sodium, random blood sugar, AST, ALT, blood urea and serum creatinine than survivors. Conversely, serum potassium level was significantly decreased in nonsurvivors than survivor patients.

Electrocardiogram changes were significantly associated with mortality where the majority of survivors $(98.3 \%)$ had normal ECG, while, 34\% of non-survivors had sinus tachycardia. Likewise, metabolic acidosis was significantly associated with mortality as it was detected in $80.9 \%$ of non survivors (Table 6 ).

Table (7) demonstrated that, non-survivors were significantly required endotracheal intubation, mechanical ventilation and received dopamine and nor adrenaline more than survivors. However, administration of $\mathrm{Mg}$ sulphate was significantly associated with improve patients outcome. The hospitalization period was significantly increased in survivor than non-survivors.

A binary logistic regression analysis was performed to determine the effects of clinically relevant variables on the probability that participants have poor outcome. The logistic regression model was statistically significant, $\chi 2=93.101, \mathrm{p}<0.001$. The model explained $78.7 \%$ (R2) of the variation in the patients outcome and correctly predicted (percentage of cases correctly classified by the independent variables as being survived or non-survived) $91.4 \%$ of cases. The presence of abnormal ECG was associated with high risk of mortality (odds ratio was 48.488) followed by presence of metabolic acidosis and hypotension (odds ratio were 10.251 and 0.964 respectively) (Table 8 ).

Table (1): Percentage of distribution and mortality rates of acute poisoned cases and acute aluminum phosphide poisoned cases admitted to Tanta Poison Control Unit from 2012 to 2016

\begin{tabular}{|c|c|c|c|c|}
\hline Years & $\begin{array}{c}\text { Total } \\
\text { admission cases } \\
\mathbf{n ( \% )}\end{array}$ & $\begin{array}{c}\text { Total } \\
\text { mortality cases } \\
\mathbf{n}(\%)\end{array}$ & $\begin{array}{c}\text { Aluminum phosphide } \\
\text { poisoned cases } \\
\mathbf{n}(\%)\end{array}$ & $\begin{array}{c}\text { Aluminum } \\
\text { phosphide deaths } \\
\mathbf{n}(\%)\end{array}$ \\
\hline 2012 & $968(10.30 \%)$ & $14(18.18 \%)$ & $21(20 \%)$ & $7(14.8 \%)$ \\
\hline 2013 & $1413(15.04 \%)$ & $7(9.09 \%)$ & $7(6.66 \%)$ & $3(6.3 \%)$ \\
\hline 2014 & $2326(24.76 \%)$ & $7(9.09 \%)$ & $14(13.33 \%)$ & $4(8.5 \%)$ \\
\hline 2015 & $2891(30.77 \%)$ & $16(20.77 \%)$ & $26(24.76 \%)$ & $11(23.4 \%)$ \\
\hline 2016 & $1796(19.11 \%)$ & $33(42.85 \%)$ & $37(35.23 \%$ & $22(46.8 \%)$ \\
\hline Total & $9394(100 \%)$ & $77(100 \%)$ & $105(100 \%)$ & $47(100 \%)$ \\
\hline
\end{tabular}

n: number

Table (2): Chi Square \& Mann Whitney tests for the association between sociodemographic, toxicological data and the patients' outcome $(n=105)$

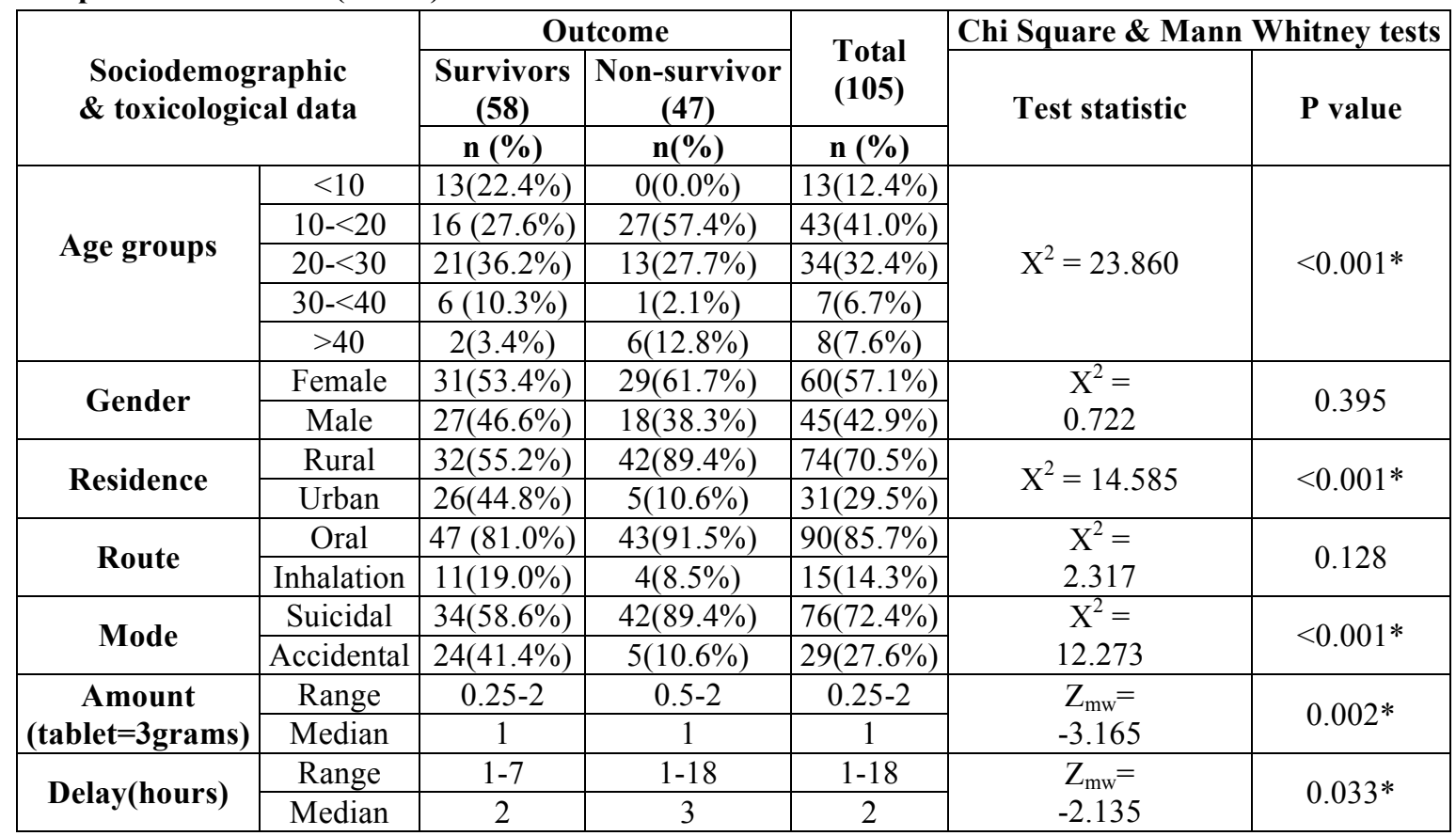

$n:$ number * significant at $p$ value $<.05$ 
Table (3): Statistical analysis (Mann Whitney test) of vital data and 02 saturation among survivors and non survivors $(\mathbf{n}=\mathbf{1 0 5})$

\begin{tabular}{|c|c|c|c|c|c|c|}
\hline \multirow{2}{*}{\multicolumn{2}{|c|}{ Vital data }} & \multicolumn{2}{|c|}{ Outcome } & \multirow{3}{*}{$\begin{array}{l}\begin{array}{l}\text { Total } \\
(\mathbf{1 0 5})\end{array} \\
0-160 \\
\end{array}$} & \multicolumn{2}{|c|}{ Mann Whitney test } \\
\hline & & \multirow{2}{*}{$\frac{\text { Survivors (58) }}{62-160}$} & \multirow{2}{*}{$\begin{array}{c}\text { Non- survivor (47) } \\
0-143 \\
\end{array}$} & & \multirow{3}{*}{$\begin{array}{c}\mathbf{Z}_{\mathrm{mw}} \\
0.864\end{array}$} & \multirow{3}{*}{$\begin{array}{c}\text { P value } \\
0.387\end{array}$} \\
\hline \multirow{2}{*}{ Pulse } & Range & & & & & \\
\hline & Median & 99.00 & 104.00 & 100 & & \\
\hline \multirow{2}{*}{$\begin{array}{l}\text { Systolic blood } \\
\text { pressure }\end{array}$} & Range & $60-160$ & $0-150$ & $0-160$ & \multirow{2}{*}{6.53} & \multirow{2}{*}{$<0.001 *$} \\
\hline & Median & 105.00 & 60.00 & 90 & & \\
\hline \multirow{2}{*}{$\begin{array}{l}\text { Diastolic blood } \\
\text { pressure }\end{array}$} & Range & $30-100$ & $0-70$ & $0-100$ & \multirow{2}{*}{6.78} & \multirow{2}{*}{$<0.001 *$} \\
\hline & Median & 70 & 40 & 50 & & \\
\hline \multirow{2}{*}{ Respiratory rate } & Range & $14-40$ & $18-55$ & $14-55$ & \multirow{2}{*}{0.864} & \multirow{2}{*}{0.387} \\
\hline & Median & 25 & 31 & 28.00 & & \\
\hline \multirow{2}{*}{ Temperature } & Range & $36-39$ & $36-38$ & $36-39$ & \multirow{2}{*}{0.989} & \multirow{2}{*}{0.323} \\
\hline & Median & 37 & 37 & 37 & & \\
\hline \multirow{2}{*}{$\mathrm{O} 2$ saturation } & Range & $91-99$ & $50-98$ & $50-99$ & \multirow{2}{*}{-6.44} & \multirow{2}{*}{$<0.001 *$} \\
\hline & Median & 97 & 94 & 96 & & \\
\hline
\end{tabular}

*Significant at $p$ value $\leq 0.05$

Table (4): Statistical analysis (Chi square test) for the association between clinical data and the patients' outcome $(n=105)$

\begin{tabular}{|c|c|c|c|c|c|c|}
\hline \multirow{2}{*}{\multicolumn{2}{|c|}{ Clinical data }} & \multicolumn{2}{|c|}{ Outcome } & \multirow{3}{*}{\begin{tabular}{|c|} 
Total (105) \\
n (\%) \\
\end{tabular}} & \multicolumn{2}{|c|}{ Chi square test } \\
\hline & & \multirow{2}{*}{$\begin{array}{c}\text { Survivors (58) } \\
\text { n (\%) }\end{array}$} & \multirow{2}{*}{$\begin{array}{c}\text { Non-survivors (47) } \\
\text { n (\%) }\end{array}$} & & \multirow{2}{*}{$\mathbf{X} 2$} & \multirow{2}{*}{ p-value } \\
\hline & & & & & & \\
\hline \multirow{4}{*}{ GCS } & Normal & $52(89.7 \%)$ & $12(25.5 \%)$ & $69(65.7 \%)$ & \multirow{4}{*}{37.14} & \multirow{4}{*}{$<0.001^{*}$} \\
\hline & Mild & $5(8.6 \%)$ & $12(25.5 \%)$ & $17(16.2 \%)$ & & \\
\hline & Moderate & $1(1.7 \%)$ & $6(12.8 \%)$ & $7(6.7 \%)$ & & \\
\hline & Severe & $0(0.0 \%)$ & $17(36.2 \%)$ & $12(11.4 \%)$ & & \\
\hline \multirow{4}{*}{ PSS } & Normal & $21(36.2 \%)$ & $0(0.0 \%)$ & $21(20.0 \%)$ & \multirow{4}{*}{80.39} & \multirow{4}{*}{$<0.001^{*}$} \\
\hline & Mild & $36(62.1 \%)$ & $6(12.8 \%)$ & $42(40.0 \%)$ & & \\
\hline & Moderate & $1(1.7 \%)$ & $16(34.0 \%)$ & $17(16.2 \%)$ & & \\
\hline & Severe & $0(0 \%)$ & $25(53.2 \%)$ & $25(23.8 \%)$ & & \\
\hline \multirow{2}{*}{ Agitation } & Yes & $0(0 \%)$ & $13(27.7 \%)$ & $13(12.4 \%)$ & \multirow{2}{*}{18.4} & \multirow{2}{*}{$<0.001 *$} \\
\hline & No & $58(100 \%)$ & $34(72.3 \%)$ & $92(87.6 \%)$ & & \\
\hline \multirow{4}{*}{ GIT } & Normal & $12(20.7 \%)$ & $5(10.6 \%)$ & $17(16.2 \%)$ & \multirow{4}{*}{3.09} & \multirow{4}{*}{0.377} \\
\hline & Vomiting & $25(43.1 \%)$ & $19(40.4 \%)$ & $44(41.9 \%)$ & & \\
\hline & abdominal pain & $13(22.4 \%)$ & $12(25.5 \%)$ & $25(23.8 \%)$ & & \\
\hline & Mixed & $8(13.8 \%)$ & $11(23.4 \%)$ & $19(18.1 \%)$ & & \\
\hline
\end{tabular}

n: number, GCS: Galscow Coma Score, PSS: Poisoning severity score, GIT: gastrointestinal tract

* Significant at $p$ value $<0.05$,

Table (5): Statistical analysis (Mann Whitney test and Student's t test) of laboratory investigations between survivors and non-survivors $(\mathbf{n}=\mathbf{1 0 5})$

\begin{tabular}{|c|c|c|c|c|c|c|}
\hline \multirow{2}{*}{\multicolumn{2}{|c|}{ Laboratory investigations data }} & \multicolumn{2}{|c|}{$\begin{array}{l}\text { Outcome } \\
\end{array}$} & \multirow{2}{*}{$\begin{array}{l}\text { Total } \\
(105)\end{array}$} & \multicolumn{2}{|c|}{ Mann Whitney\& Student's t test } \\
\hline & & \multirow{2}{*}{$\begin{array}{c}\text { Survivors (58) } \\
128-149\end{array}$} & \multirow{2}{*}{$\begin{array}{c}\text { Non -survivor (47) } \\
130-154\end{array}$} & & Test statistic & P value \\
\hline Serum sodium level & Range & & & $128-154$ & \multirow{2}{*}{$\mathbf{Z}_{\mathbf{m w}}=-3.58$} & \multirow{2}{*}{$<0.001 *$} \\
\hline$(\mathrm{mEq} / \mathrm{L})$ & Median & 139.00 & 142.00 & 140.00 & & \\
\hline \multirow{2}{*}{ Serum potassium $(\mathrm{mEq} / \mathrm{L})$} & Range & $2.60-5$ & $2.10-4.20$ & $2.10-5.00$ & \multirow{2}{*}{$\mathbf{t}=-7.35$} & \multirow{2}{*}{$<0.001 *$} \\
\hline & Mean \pm SD & $3.69 \pm .52$ & $2.96 \pm .49$ & $3.36 \pm .62$ & & \\
\hline \multirow{2}{*}{$\begin{array}{l}\text { Random blood sugar } \\
(\mathrm{mg} / \mathrm{dl})\end{array}$} & Range & $79-180$ & $42-308$ & $42-308$ & \multirow{2}{*}{$\mathbf{Z}_{\mathbf{m w}}=-4.69$} & \multirow{2}{*}{$<0.001 *$} \\
\hline & Median & 109.00 & 159.00 & 120.00 & & \\
\hline \multirow{2}{*}{$\begin{array}{c}\text { Serum aspartate } \\
\text { aminotransferase }(\mathrm{U} / \mathrm{L})\end{array}$} & Range & $10-46$ & $6-155$ & $6-155$ & \multirow{2}{*}{$\mathbf{Z}_{\mathbf{m w}}=-2.66$} & \multirow{2}{*}{$0.001 *$} \\
\hline & Median & 22 & 25 & 22 & & \\
\hline \multirow{2}{*}{$\begin{array}{c}\text { Serum alanine } \\
\text { aminotransferase }(\mathrm{U} / \mathrm{L})\end{array}$} & Range & $10-45$ & $10-85$ & $10-85$ & \multirow{2}{*}{$\mathbf{Z}_{\mathbf{m w}}=-2.46$} & \multirow{2}{*}{$0.014 *$} \\
\hline & Median & 22.00 & 30.00 & 22.00 & & \\
\hline \multirow{2}{*}{ Blood urea (mg/dl) } & Range & $17-50$ & $19-55$ & $17-55$ & \multirow{2}{*}{$\mathbf{t}=2.88$} & \multirow{2}{*}{$0.005^{*}$} \\
\hline & Mean \pm SD & $32.21 \pm 6.71$ & $36.32 \pm 7.92$ & $34.05 \pm 7.53$ & & \\
\hline Serum creatinine $(\mathrm{mg} / \mathrm{dl})$ & Range & $0.60-1.20$ & $0.90-5.50$ & $0.60-5.50$ & $\mathbf{Z}_{\mathbf{m w}}=-7.403$ & $<0.001 *$ \\
\hline
\end{tabular}




\begin{tabular}{|c|c|c|c|c|c|c|}
\hline \multicolumn{2}{|c|}{\begin{tabular}{l|l} 
& Medi \\
\end{tabular}} & \multicolumn{2}{|r|}{1.20} & \multicolumn{2}{|r|}{0.90} & \\
\hline \multicolumn{7}{|c|}{$\begin{array}{l}\text { * Significant at } p \text { value }<0.05 \\
\text { Table (6): Statistical analysis (Chi square test) of ECG finding and acid base disturbance betwee } \\
\text { non-survivors }(\mathbf{n}=\mathbf{1 0 5})\end{array}$} \\
\hline \multirow{3}{*}{\multicolumn{2}{|c|}{ Parameter }} & \multicolumn{2}{|c|}{\begin{tabular}{|l|} 
Outcome \\
\end{tabular}} & \multirow{3}{*}{\begin{tabular}{l|l|} 
Total \\
$(105)$
\end{tabular}} & \multicolumn{2}{|c|}{ Chi square test } \\
\hline & & \multirow{2}{*}{\begin{tabular}{|c|} 
Survivors (58) \\
n (\%) \\
\end{tabular}} & \multirow{2}{*}{$\begin{array}{c}\text { Non-survivors (47) } \\
n(\%) \\
\end{array}$} & & \multirow{2}{*}{$\mathrm{X} 2$} & \multirow{2}{*}{ p-value } \\
\hline & & & & & & \\
\hline \multirow{5}{*}{$\begin{array}{l}\mathrm{ECG} \\
\text { finding }\end{array}$} & Normal & $57(98.3 \%)$ & $13(27.7 \%)$ & $70(66.7 \%)$ & \multirow{5}{*}{62.12} & \multirow{5}{*}{$<0.001 *$} \\
\hline & Sinus tachycardia & $1(1.7 \%)$ & $16(34.0 \%)$ & $17(16.2 \%)$ & & \\
\hline & Ventricular fibrillation & $0(0.0 \%)$ & $13(27.7 \%)$ & $13(12.4 \%)$ & & \\
\hline & Atrial fibrillation & $0(0.0 \%)$ & $3(6.4 \%)$ & $3(2.9 \%)$ & & \\
\hline & Depressed ST segment & $0(0.0 \%)$ & $2(4.3 \%)$ & $2(1.9 \%)$ & & \\
\hline \multirow{5}{*}{$\begin{array}{l}\text { Acid-base } \\
\text { disturbance }\end{array}$} & Normal & $45(77.6 \%)$ & $4(8.5 \%)$ & $49(46.7 \%)$ & \multirow{5}{*}{64.78} & \multirow{5}{*}{$<0.001 *$} \\
\hline & Metabolic acidosis & $8(13.8 \%)$ & $38(80.9 \%)$ & $46(43.8 \%)$ & & \\
\hline & Respiratory alkalosis & $3(5.2 \%)$ & $0(0.0 \%)$ & $3(2.9 \%)$ & & \\
\hline & Mixed disorder & $1(1.7 \%)$ & $5(10.6 \%)$ & $6(5.7 \%)$ & & \\
\hline & Metabolic alkalosis & $1(1.7 \%)$ & $0(0.0 \%)$ & $1(1.0 \%)$ & & \\
\hline
\end{tabular}

n: number; ECG: electrocardiograph, * Significant at $p$ value $<0.05$

Table (7): Statistical analysis (Chi Square and Mann Whitney test) of treatment data and length of hospital stay between survivors and non-survivors $(n=105)$

\begin{tabular}{|c|c|c|c|c|c|c|}
\hline \multirow{2}{*}{\multicolumn{2}{|c|}{ Treatment \& hospital stay }} & \multicolumn{2}{|c|}{\begin{tabular}{|c|} 
Outcome \\
\end{tabular}} & \multirow{3}{*}{$\begin{array}{c}\begin{array}{c}\text { Total } \\
(105)\end{array} \\
\text { n (\%) } \\
\end{array}$} & \multicolumn{2}{|c|}{ Chi Square \& Mann Whitney tests } \\
\hline & & \multirow{2}{*}{$\begin{array}{c}\text { Survivors(58) } \\
\text { n (\%) } \\
\end{array}$} & \multirow{2}{*}{$\begin{array}{c}\text { Non-survivor(47) } \\
\text { n (\%) } \\
\end{array}$} & & \multirow{2}{*}{ Test statistic } & \multirow{2}{*}{$P$ value } \\
\hline \multirow{3}{*}{ Endotracheal intubation } & & & & & & \\
\hline & Yes & $2(3.4 \%)$ & $41(87.2 \%)$ & $43(41.0 \%)$ & \multirow{2}{*}{$\mathbf{X}^{2}=75.37$} & \multirow{2}{*}{$<0.001 *$} \\
\hline & No & $56(96.6 \%)$ & $6(12.8 \%)$ & $62(59.0 \%)$ & & \\
\hline \multirow{2}{*}{ Mechanical ventilation } & Yes & $2(3.4 \%)$ & $17(36.2 \%)$ & $19(18.1 \%)$ & \multirow{2}{*}{$\mathbf{X}^{\mathbf{2}}=18.76$} & \multirow{2}{*}{$<0.001 *$} \\
\hline & No & $56(96.6 \%)$ & $30(63.8 \%)$ & $86(81.9 \%)$ & & \\
\hline \multirow{2}{*}{ Dopamine } & Yes & $11(19.0 \%)$ & $35(74.5 \%)$ & $46(43.8 \%)$ & \multirow{2}{*}{$\mathbf{X}^{\mathbf{2}}=32.48$} & \multirow{2}{*}{$<0.001 *$} \\
\hline & No & $47(81.0 \%)$ & $12(25.5 \%)$ & $59(56.2 \%)$ & & \\
\hline \multirow{2}{*}{ Nor adrenaline } & Yes & $0(0.0 \%)$ & $31(66.0 \%)$ & $31(29.5 \%)$ & \multirow{2}{*}{$\mathbf{X}^{2}=54.28$} & \multirow{2}{*}{$<0.001 *$} \\
\hline & No & $58(100.0 \%)$ & $16(34.0 \%)$ & $74(70.5 \%)$ & & \\
\hline \multirow{2}{*}{ Mg sulphate } & Yes & $20(34.5 \%)$ & $2(4.3 \%)$ & $22(21.0 \%)$ & \multirow{2}{*}{$\mathbf{X}^{\mathbf{2}}=14.32$} & \multirow{2}{*}{$<0.001 *$} \\
\hline & No & $38(65.5 \%)$ & $45(95.7 \%)$ & $83(79.0 \%)$ & & \\
\hline \multirow{2}{*}{ Hospital stay (h) } & Range & $12-360$ & $2-72$ & $2-360$ & \multirow{2}{*}{$\begin{array}{c}\mathbf{Z}_{\mathbf{m w}=} \\
7.69 \\
\end{array}$} & \multirow{2}{*}{$<0.001 *$} \\
\hline & Median & 24 & 9 & 22 & & \\
\hline
\end{tabular}

n: number, * Significant at $p$ value $<0.05$

Table (8): A binary logistic regression for prediction of mortality in aluminum phosphide poisoned patients (n=104)

\begin{tabular}{|c|c|c|c|c|c|c|c|}
\hline Variables & B coefficient & Odds ratio & $P$ value & $\begin{array}{c}\text { Overall } \\
\text { accuracy }\end{array}$ & $\mathbf{R}^{2}$ & $\mathbf{X}^{2}$ & $P$ value \\
\hline Metabolic acidosis & 2.327 & 10.251 & $0.002^{*}$ & \multirow{3}{*}{$91.4 \%$} & \multirow{3}{*}{$78.7 \%$} & \multirow{3}{*}{93.101} & \multirow{3}{*}{$<0.001 *$} \\
\hline Systolic blood pressure & $-.036-$ & 0.964 & $0.008^{*}$ & & & & \\
\hline Electrocardiograph changes & 3.881 & 48.488 & $0.002 *$ & & & & \\
\hline
\end{tabular}

* Significant at $p$ value $<0.05$

\section{Discussion}

In recent years, incidence of acute aluminum phosphide poisoning is increasing steadily with higher mortality rates especially in developing countries due to wide accessibility and its cheapness in price (Chugh, 1992; Moghadamnia, 2012). Determination of the prognostic factors of mortality is an important step to improve management and patients' outcomes. Therefore, the aim of this study was to evaluate the predictive factors of mortality from acute ALP poisoned cases admitted to Tanta Poison Control Unit in a 5years interval the start of January 2012 to the end of December 2016.

In the present study, 105 acute ALP poisoned patients were admitted to Tanta Poison Control Unit in a 5years interval with $47(44.7 \%)$ death rate. This result coincides with Indian study by Louriz et al. (2009); Iranian study by Nejad et al.(2012); Albanian 
study by Sulaj et al. (2015) who reported that the mortality rates of acute ALP poisoning were $49 \%, 41.8 \%$ and $44.1 \%$ respectively. The present study demonstrated uprising rate of the mortality from $6.3 \%$ at 2013 to $48.8 \%$ in 2016. This could be attributed to uncontrolled marketing, cheapness of ALP, lacking of knowledge in social media about ALP health hazards and absence of specific antidote treatment (Sulaj et al., 2015; HashemiDomeneh et al., 2016 ).

The current study revealed that the majority of patients $(41 \%)$ were in age group 10-20 years with significant difference between both groups. The greater part of patients was females $(57.1 \%)$. This result is in partial agreement with Sulaj et al. (2015) who reported that the highest incidence of mortality $(15.7 \%)$ was between 16-19 years with female preponderance. Saha et al. (2014) demonstrated that the majority of acute ALP poisoned cases $(68 \%)$ was in age group 15-25 years. Conversely, many studies noted that the majority of acute ALP poisoned patients was between 20-30 years with dominance of males (Khurana et al., 2011; Parmar et al., 2015). Female adolescents are obviously at a higher risk in the current study as they are more exposed to psychic troubles in family, emotional and educational problems making them more liable for suicidal attempts.

Additionally, the majority of patients (70.5\%) were from nearby rural region in the present study. Likewise, Mehrpour et al. (2012);Parmar et al. (2015) demonstrated that ALP is widely used in farming activity without restriction and lack of awareness could increase its incidence in rural regions.

In the present study, most cases take ALP orally $(85.7 \%)$ in suicidal attempts $(72.4 \%)$ with significant increases in non-survivors. This result was in line with Etemadi-Aleagha et al. (2015) who reported that suicide accounted for $85 \%$ of fatal ALPP. Eddleston, (2004) reported that ALP is commonly used as a method for committing suicide by ingestion in many developing countries.

The current study demonstrated that, the amount of ingestion ranged from 0.25 to two tablets with significant association with mortality. This finding is parallel to Boukatta et al. (2013) who reported that the range of ingested tablet was 0.25 to three tablets. Additionally, Hosseinian et al. (2011) demonstrated a significant increase of ingested tablets in non-survivors than survivors.

The median of pre-hospitalization period was 2 hours and was significantly longer in non-survivors than survivors in the current study. This result is in agreement with Mathai and Bhanu, (2010); Hosseinian et al. (2011); Shahin et al. (2016) who reported that the mean of delay was $2.1 \pm 1.55,2.14 \pm 5.02$ and 2 hours respectively. The short delay period in the present study could be explained by easily and quick absorption of ALP that may resulting in short time interval between ingestion and the appearance of clinical manifestations (Mostafazadeh, 2012). Moreover, the majority of patients in the present study did not actually intend to end their lives but they just try to draw attention and gain help and compassion from their families, so, they rapidly seek for medical treatment.

The present study revealed that non-survivors had significantly lower systolic and diastolic blood pressure than survivor group. This finding coincides with Louriz et al. (2009); Boukatta et al. (2013) who demonstrated significant association between SBP and mortality. It could be attributed to massive intravascular fluid loss as a result of vascular wall insufficiency that happens after phosphine gas absorption causing hypovolemic shock (Marashi et al., 2011; Farahani 2016). Moreover, phosphine gas has a direct cardiotoxic effects that induce profound circulatory collapse (Proudfoot, 2009; Moghadamnia, 2012).

The current study revealed that the majority of non-survivor group $(36.2 \%)$ had severe GCS and there was a significant association between each of GCS, and agitations with patients' mortality. This finding is parallel to Sulaj et al. (2015) who reported that $37 \%$ of fatal ALP poisoned patients had coma (GCS $<7)$. This could explained by effect of phosphine gas on central nervous system that range from headache and irritability to altered mental status, although, these manifestations are not prominent unless hypoxia and hypotension occur (Louriz et al., 2009; Hashemi-Domeneh et al., 2016).Moreover, the greater part of non-survivors (53.2\%) had severe PSS. This could be explained by inhibition of cytochrome-coxidase ezyme and oxidative phosphorylation by phosphine gas causing multi-organ damage (Mehrpour et al., 2012).

Regarding arterial blood gases, the present study revealed that $43.8 \%$ of patients had metabolic acidosis, which was significantly associated with mortality. This finding is in accordance with Hosseinian et al. (2011) who demonstrated that $41.1 \%$ of patients had metabolic acidosis and the non-survivor group had significantly decrease $\mathrm{pH}$ and low $\mathrm{HCO} 3$ than survivor group. It could be attributed to accumulation of lactic acid as a result of inhibition of oxidative phosphorylation and poor tissue perfusion that result from the irreversible shock (Gurjar et al., 2011). Accordingly, the present study revealed significant association between $\mathrm{O}_{2}$ Saturation and mortality, which is in line with Hosseinian et al. (2011).

The current study demonstrated that, nonsurvivors had significantly lower serum potassium level than survivors, which is in agreement with Boukatta et al. (2013). Hypokalemia may be caused by vomiting after tablet ingestion or due to catecholamine release (Proudfoot, 2009).On contrary, serum sodium level and random blood sugar were significantly increased in nonsurvivors than survivors in the present study. These finding coincide with Hosseinian et al. (2011) who reported significant association between each of hypernatremia, hyperglycemia and mortality. Aluminum phosphide poisoning may cause either increase or decrease in serum sodium and random blood sugar, which 
are associated with poor outcome (Chugh et al., 2000; Frangides and Pneumatikos, 2002; Mehrpour et al., 2008).

The current study revealed that elevated AST, ALT, blood urea and serum creatinine were significantly associated with mortality. These results are in agreement with Louriz et al. (2009); Hosseinian et al. (2011) who reported that hepatic dysfunction was associated with poor prognosis. Moreover, Mathai and Bhanu (2010) demonstrated that elevated serum creatinine was associated with mortality. These finding could be explained by inhibition of cytochrome $\mathrm{c}$ oxidase and free radical damage as the toxic effects of phosphine gas. Additionally, these organs are more susceptible to the hypoxic damage induced by phosphine gas due to their greatest oxygen requirement (Louriz et al., 2009; Hashemi-Domeneh et al., 2016). These finding are comparable with the post-mortem histopathological finding in these organs (Sinha et al., 2005).

The study revealed significant association between ECG changes with mortality. The majority of non survivors $(34 \%)$ had sinus tachycardia followed by ventricular fibrillation (27.7\%) and atrial fibrillation (6.4\%). Various studies reported an association of cardiac dysrhythmia with mortality (Kalra et al., 1991; Lall et al., 1997; Hosseinian et al., 2011). Katira et al.(1990) reported that sinus tachycardia was a dominant finding in the first hours of admission, while ST segment changes and conduction arrhythmias appear in the later period. These changes could be attributed to inhibition of cytochrome $\mathrm{c}$ oxidase in myocardial tissue, focal myocardial necrosis by the effect of free radical generation and electrolyte disturbances (Singh et al., 2006; Akkaoui et al., 2007). These effects may cause alteration of cardiac transmembrane and ischemic like effects on ECG (El-Ebiary et al., 2015).

The present study demonstrated that the need for mechanical ventilation and the use of vasoactive drugs as dopamine and noradrenaline were significantly associated with mortality. These findings are in line with Louriz et al. (2009); Mathai and Bhanu (2010); Nejad et al. (2012);Boukatta et al. (2013). The need of endotracheal intubation and mechanical ventilation depend on severity of hypoxia, acute lung injury and poor mental status (Gurjar et al.2011).Likewise, the use of vasoactive drugs were used as a second step for treatment of hemodynamic instability and persistent shock after failure of massive crystalloid administration (Baeerirt al., 2013; Hashemi-Domeneh et al., 2016).

On the other hand, the present study demonstrated that administration of $\mathrm{Mg}$ sulphate was significantly associated with improvement in patients' outcome. This result coincides with Chugh et al. (1997) who reported significant improvement of oxidative stress markers and lower mortality incidence after repeated doses of $\mathrm{Mg}$ suphlate. It could be explained that administration of $\mathrm{Mg}$ sulphate may decrease the incidence of cardiac arrhythmias by membrane stabilizing and antioxidation effects (Gurjar et al., 2011).However, some previous studies did not demonstrate any association between $\mathrm{Mg}$ sulphate administration and improvement of survival period (Siwach et al., 1995).

The hospitalization period was significantly decreased in non-survivor than survivors, which is in line withSinghai et al. (2014). This could be explained by the fast progression of symptoms to be life-threatening condition within short period (Singh et al., 2014).Many studies have reported that the average survival period was 3 hours (1-48 hours), $95 \%$ of non-survivors died within 24 hours and cardiac arrhythmias was the commonest cause of mortality(Singh et al., 1996, Wahab et al., 2008; Moghadamnia, 2012).

In the current study, the logistic regression model revealed that the presence of abnormal ECG was associated with high risk of mortality (odds ratio was 48.488) followed by presence of metabolic acidosis and hypotension (odds ratio were 10.251 and 0.964 respectively). In agreement with this finding, Louriz et al. (2009) demonstrated that the presence of shock was significantly associated with mortality in cases of aluminum phosphide poisoning with relative risk of 3.82 . Additionally, Nejad et al. (2012) revealed by logistic regression analysis similar high risk of mortality (relative risk $=43$ ) of ECG abnormalities.

Wahab et al. (2008) concluded that the development of refractory shock, aspiration pneumonitis, adult respiratory distress syndrome, metabolic acidosis, severe hypoxia, electrolyte imbalance, coma, gastrointestinal bleeding, anemia and pericarditis were significantly associated with poor prognosis. However, from the factors associating with poor patients outcome, cardiocirculatory collapse and metabolic acidosis are probably the most important ones that do not respond to conventional management (Singh et al., 1996; Bogle et al., 2006; Shadnia et al., 2010; Gurjar et al., 2011; Hassanian-Moghaddam and Zamani 2016). and showed that the outcome of acute ALP poisoning is mainly determined by the presence or absence of severe metabolic acidosis and persistent hypotension. Likewise, many previous studies reported that nearly all nonsurvivors had ECG abnormality and cardiovascular collapse at admission (Hosseinian et al., 2011; Singhai et al., 2014).Mohan et al. (2016) demonstrated that, the mortality rate of ALP is approximately $100 \%$ if patient presented with severe left ventricular dysfunction, severe metabolic acidosis and resistant hypotension.

\section{Conclusion}

The mortality incidence of acute ALP poisoning is increasing steadily in our locality. Therefore, there is an increasing need for recognition of predictive factors of mortality to improve patients' outcomes. At admission, presence of abnormal ECG, metabolic acidosis and hypotension, findings could be used as alarming predictive factors of mortality from acute ALP poisoning. Early management of these risk factors via intensive hemodynamic monitoring and proper supportive care might improve patients' outcome. Other risk factors of 
mortality included young age group, rural regions, suicidal ingestion, altered consciousness, low potassium level and elevated each of serum sodium, random blood sugar, liver enzymes, and blood urea and serum creatinine levels. Moreover, the need of mechanical ventilation and vasoactive drug administration, low $\mathrm{Mg}$ sulphate administration may be associated with poor outcome.

\section{Recommendations}

Prevention of poisoning is always better than management. Official heath care system should be advised to set strict roles for open ALP sales especially in young age group who is more susceptible to suicide. The ALP applicators must be licensed or working under strict supervision from Ministry of Agriculture. The manufactures should be advised to make caging of tablets in not ingestible plastic containers with small holes.

This study has some limitations including the retrospective data collection and relatively small sample size. Further prospective studies with large sample size are recommended for better evaluation of prognostic factors.

\section{References}

Agrawal VK, Bansal A, Singh RK et al., (2015): Aluminum phosphide poisoning: Possible role of supportive measures in the absence of specific antidote. Indian J Crit Care Med. 19(2):109-112.

Akkaoui M, Achour S, Abidi K et al., (2007): Reversible myocardial injury associated with aluminum phosphide poisoning. ClinToxicol (Phila). 45(6):728-731.

Baeeri M, Shariatpanahi M, Baghaei A et al., (2013): On the benefit of magnetic magnesium nanocarrier in cardiovascular toxicity of aluminum phosphide. Toxicol Ind Health. 29:126-135.

Bogle RG, Theron P, Brooks P et al., (2006): Aluminium phosphide poisoning. Emerg Med J. 23:e3.

Boukatta B, El Bouazzaoui A, Houari N et al., (2013): Statistics of acute aluminium phosphide poisoning in Fez, Morocco. Journal of Life Sciences.7:1159-1164.

Chaudhary S ,Momin S.G, Vora DH et al., (2013): An Epidemiological Study of Fatal Aluminium Phosphide Poisoning At Rajkot. IOSR Journal of Pharmacy.3 (1): 17-23.

Chugh SN (1992):Aluminum phosphide poisoning: Present status and management. J Assoc Physicians India.40:401-405.

Chugh SN, Kishore K, Aggarwal $\mathrm{N}$ et al., (2000):Hypoglycaemia in acute aluminium phosphide poisoning. J. Assoc. Physicians India. 48: 855-856.

Chugh SN, Kolley T, Kakkar R et al., (1997): A critical evaluation of anti-peroxidant effect of intravenous magnesium in acute aluminium phosphide poisoning. Magnes Res.10:225-230.

Dawson-Saunders B and Trapp R (2001): Basic and clinical biostatics. Dawson-Saunders $\mathrm{B}$ and
Trapp R (eds), 3rd ed., McGrow Hill McGrow Hill Medical Publishing Division, pp: 161-218.

Eddleston M (2004): Self poisoning with pesticides. BMJ. 328:42-44.

El-Ebiary A, Elgazzar F, Soliman MA et al., (2015): Predictors of prognosis in acute aluminum phosphide poisoning. Mansoura Journal of Forensic Medicine and Clinical Toxicology. XXIII (2):13-28.

Etemadi-Aleagha A, Akhgari M and Iravani FS (2015): Aluminum Phosphide Poisoning-Related Deaths in Tehran, Iran, 2006 to 2013. Medicine (Baltimore). 94(38):e1637.

Farahani MV, Soroosh D and Marashi SM (2016): Thoughts on the current management of acute aluminum phosphide toxicity and proposals for therapy: An evidence-based review. Indian J Crit Care Med.20:724-730.

Frangides CY and Pneumatikos IA (2002): Persistent severe hypoglycemia in acute zinc phosphide poisoning. Intensive Care Med. 28:223.

Goel A and Aggarwal P (2007): Pesticide poisoning. Natl Med J India. 20:182-191.

Gurjar M, Baronia AK, Azim A et al., (2011):Managing aluminum phosphide poisonings. J Emerg Trauma Shock. 4(3):378-384.

Hashemi-Domeneh B, Zamani N, Hassanian-Moghaddam $\mathrm{H}$ et al., (2016): A review of aluminium phosphide poisoning and a flowchart to treat it. ArhHig Rada Toksikol. 67:183-193.

Hassanian-Moghaddam H and Pajoumand A (2007): Two years epidemiological survey of aluminum phosphide poisoning in Tehran. Iranian $\mathbf{J}$ Toxicol.1:35-39.

Hassanian-Moghaddam H and Zamani N (2016): Therapeutic role of hyperinsulinemia/ euglycemia in aluminum phosphide poisoning.M edicine (Baltimore).95(31):e4349.

Hosseinian A, Pakravan N, Rafiei A et al., (2011): Aluminum phosphide poisoning known as rice tablet: a common toxicity in North Iran. Indian J Med Sci. 65:143-149.

Kalra GS, Anand IS, Jit I, Bushnurmath B, et al., (1991): Aluminium phosphide poisoning: Haemodynamic observations. Indian Heart J. 43:175-178.

Katira R, Elhance GP, Mehrotra ML et al., (1990): A study of aluminium phosphide (ALP) poisoning with special reference to electrocardiographic changes. J Assoc Physicians India. 38:471-473.

Khurana P, Dalal IS, Multani AS et al., (2011): The Study of Aluminium Phosphide Poisoning in a Tertiary Care Hospital, Amritsar. J Indian Acad Forensic Med. 33(4): 332-336.

Lall SB, Sinha K, Mittra S et al., (1997): An experimental study on cardiotoxicity of aluminium phosphide. Indian J Exp Biol. 35:1060-1064. 
Louriz M, Dendane T, Abidi K et al., (2009): Prognostic factors of acute aluminum phosphide poisoning. Indian J Med Sci. 63 (6): 227-234.

Marashi SM, Arefi M and Behnoush B (2011): Could hydroxyethyl starch be a therapeutic option in management of acute aluminum phosphide toxicity? Med Hypotheses. 76:596-598.

Mathai A and Bhanu MS (2010): Acute aluminium phosphide poisoning: Can we predict mortality? Indian J Anaesth. 54:302-307.

Meena MC, Mittal S and Rani Y (2015):Fatal aluminium phosphide poisoning. Interdiscip Toxicol. $8(2): 65-67$.

Mehrpour O, Alfred S, Shadnia S et al., (2008): Hyperglycemia in acute aluminum phosphide poisoning as a potential prognostic factor. Human \& Experimental Toxicology. 27: 591595.

Mehrpour O, Jafarzadeh M and Abdollahi M (2012): A systematic review of aluminium phosphide poisoning. Arh Hig Rada Toksikol.63(1):61-73.

Moghadamnia AA (2012):An update on toxicology of aluminum phosphide. Moghadamnia DARU Journal of Pharmaceutical Sciences. 20:25.

Mohan B, Singh B, Gupta V et al., (2016): Outcome of patients supported by extracorporeal membrane oxygenation for aluminum phosphide poisoning: An observational study. Indian Heart J. 68(3):295-301.

Mostafazadeh B (2012):Aluminium Phosphide Poisoning in: Toxicity and Drug Testing Toxicity and Drug Testing, Acree B (ed), pp :345-360.

Nejad FT, Mohammadi AB, Behnoush B et al., (2012): Predictors of poor prognosis in aluminium phosphide intoxication. Iran J Toxicol.6:610614.

Parmar P, Rathod G, Rathod S, et al., (2015): Demographic profile of Aluminium phosphide poisoning in Gandhinagar, Gujarat. International Archives of Integrated Medicine. 2(1): 76-82.

Persson H, Sjöberg G, Haines J et al., (1998): Poisoning Severity Score: Grading of acute poisoning. J Toxicology - Clinical Toxicology. 36:205-213.

Proudfoot AT (2009):Aluminium and zinc phosphide poisoning. ClinToxicol (Phila). 47: 89-100.

Saha JK, Azad AK,Hossain MZ et al., (2014) :Aluminium phosphide poisoning cases in a tertiary care hospital. Journal of Dhaka Medical College. 23(1): 3-6.

Saidi H and Shojaie S (2012): Effect of sweet almond oil on survival rate and plasma cholinesterase activity of aluminum phosphide-intoxicated rats. Hum ExpToxicol. 31:518- 522.

Shadnia S, Mehrpour O and Soltaninejad K (2010): A simplified acute physiology score in the prediction of acute aluminum phosphide poisoning outcome. Indian J Med Sci. 64:532539.

Shahin MM, Abuelfadl AA and Zaki ANM (2016): The potential role of S-100 $\beta$ protein in evaluation of CNS affection and prediction of mortality in acute phosphides intoxication. Ain Shams Journal of Forensic Medicine and Clinical Toxicology. 26: 7-15.

Singh S, Bhalla A, Verma SK et al., (2006): Cytochromec oxidase inhibition in 26 aluminum phosphide poisoned patients. ClinToxicol (Phila). 44: 155158.

Singh S, Singh D, Wig N et al., (1996):Aluminum phosphide poisoning: a clinicopathologic study. J ToxicolClinToxicol. 34:703-706.

Singh Y, Joshi SC, Satyawali V et al., (2014): Acute aluminium phosphide poisoning, what is new? The Egyptian journal of internal medicine. 26 (3): 99-103.

Singh Y, Joshi SC, Satyawali V et al., (2014): Acute aluminium phosphide poisoning, what is new? The Egyptian journal of internal medicine. 26 (3): 99-103.

Singhai A, Parmar D, Banzal S et al., (2014): Clinical profile of celphos poisoning in central India. Int J Adv Med. 1(2):86-88.

Sinha US, Kapoor AK, Singh AK et al., (2005): Histopathological changes in cases of aluminium phosphide poisoning. Indian J Pathol Microbiol. 48(2):177-180.

Siwach SB, Dua A, Sharma R et al., (1995): Tissue magnesium content and histopathological changes in non-survivors of aluminium phosphide poisoning. J Assoc Physicians India. 43:676-678.

Sulaj Z, Drishti A, ÇekoI et al., (2015):Fatal aluminum phosphide poisonings in Tirana (Albania), 2009 2013. DARU Journal of Pharmaceutical Sciences.25: 23-28.

Taghaddosinejad F, Farzaneh E, Ghazanfari-Nasrabad M et al., (2016): The effect of $\mathrm{N}$-acetyl cysteine (NAC) on aluminum phosphide poisoning inducing cardiovascular toxicity: a case-control study. Springerplus. 5(1):1948.

Teasdale G and Jennett B (1974): Assessment of coma and impaired consciousness. Lancet 1974; 81-84.

Wahab A, Zaheer MS, Wahab S et al., (2008): Acute aluminium phosphide poisoning: An update. Hong Kong J Emerg Med.15:152-155.

Wahdan A and Elmadah E (2016): Methemoglobinemia and Intravascular Hemolysis; Unusual Presentations of Metal Phosphides Poisoning. Ain Shams Journal of Forensic Medicine and Clinical Toxicology. 26: 129- 139. 


\section{الملخص العربي \\ عوامل التنبؤ بوفيات التسمم الحاد بفوسفيدالألومنيوم: دراسة إسترجاعية خمس سنوات بوحدة علاج التسمم بطنطا \\ غادة نبيل السرنجاوي 1}

مقدمة: يعتبر فوسفيد الألومنيوم من أكثر مبيدات القوارض استخداما لحفظ الحبوب. ويعد التسمم الحاد بفوسفيد الألومنيوم أحد

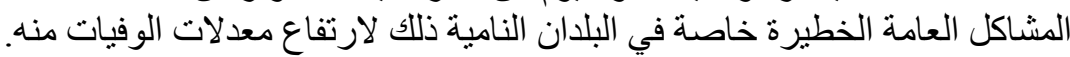

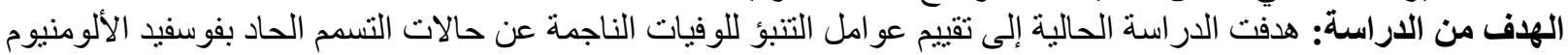

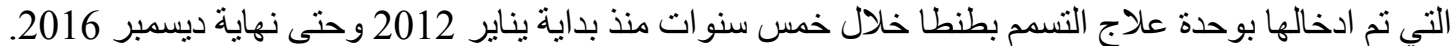

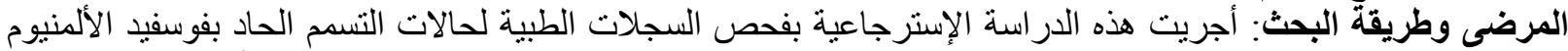

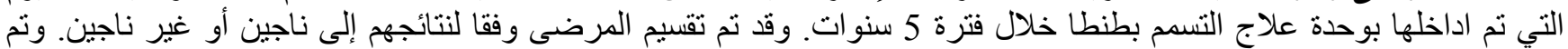

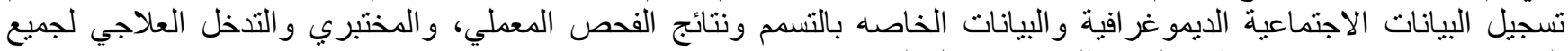

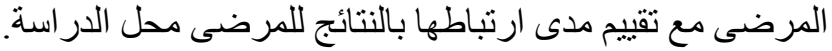

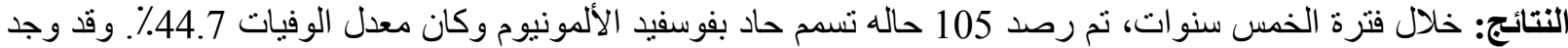

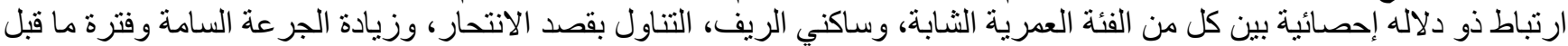

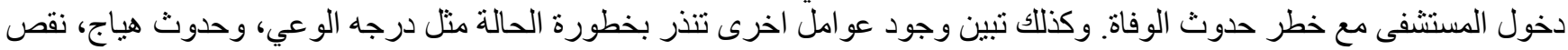

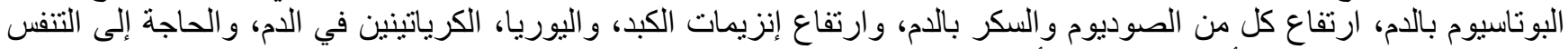

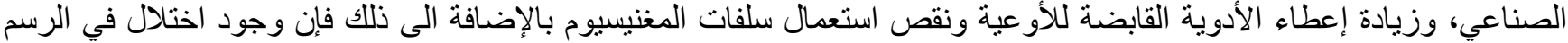

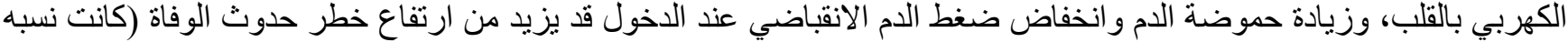

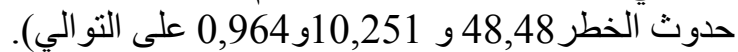

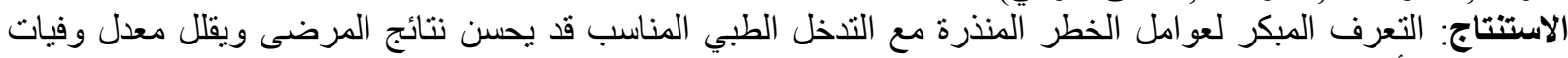

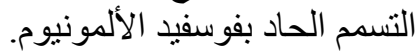
التوصيات: نظر لارتفاع تعدادالوفيات من التسمم الحاد بفوسفيد الالومونيوم فإنه يوصى بفرض قيود على على مبيعاته المفتوحه كما يوصى بتصنيعه في عبو ات آمناه غير قابله للإبتانلاع.

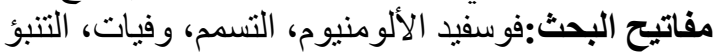

